\title{
Investigation of Interfacial Reaction Products and Stress Distribution in \\ Selective Laser Melted Al12Si/SiC Composite using Confocal Raman Microscopy
}

Xiaopeng Li, Charlie Kong, Thomas Becker, and Tim Sercombe

[*] Xiaopeng Li and Tim Sercombe

The University of Western Australia, School of Mechanical and Chemical

Engineering, Perth, WA 6009, Australia

Charlie Kong

The University of New South Wales, Electron Microscope Unit, Sydney, NSW 2052, Australia

Thomas Becker

The University of Western Australia, Centre for Microscopy, Characterisation and Analysis, Perth, WA 6009, Australia

Curtin University, Department of Chemistry, GPO Box U1987, Perth WA 6845, Australia

Corresponding author email: xiaopeng.li@kuleuven.be; tim.sercombe@uwa.edu.au

[**] This work was supported by the Australian Research Council (ARC) Discovery Project DP130103592. The authors also acknowledge the facilities, and the scientific and technical assistance of the Australian Microscopy \& Microanalysis Research Facility at the Centre for Microscopy, Characterisation \& Analysis, The University of Western Australia, a facility funded by the University, State and Commonwealth Governments. 
Abstract: In this letter, the interfacial reaction products and stress distribution in a Selective Laser Melted Al12Si/SiC composite were studied using confocal Raman microscopy. Energy dispersive X-ray spectroscopy (EDX) mapping and the Raman spectroscopy revealed that needle-like $\mathrm{Al}_{4} \mathrm{C}_{3}$ and equiaxed $\mathrm{Si}$ are located at the interface between the $\mathrm{Al}$ matrix and $\mathrm{SiC}$ particles. This reaction was triggered by the high temperature within the SiC due to its high laser absorptivity. Raman frequency shifts to lower wavenumber were observed in both the SiC and $\mathrm{Si}$, suggesting the existence of tensile stress within the interface. The tensile stress in $\mathrm{SiC}$ is estimated $570 \mathrm{MPa}$ in the build direction (Z) which was higher than the tensile stress $240 \mathrm{MPa}$ in the direction $(\mathrm{X}-\mathrm{Z})$ perpendicular to the building direction. No such difference was observed in the Si. The underlying reason was ascribed to the Gaussian distribution of the laser energy density and stress relief through the interfacial reaction.

\section{Introduction}

Aluminium metal matrix composites (AMMCs) are important engineering materials with high specific strength, excellent stiffness,tailorable thermal expansion coefficient as well as enhanced electrical performance ${ }^{[1]}$. AMMCs have found structural and functional applications in many industries including aircraft, automotive, energy storage as well as thermal management areas ${ }^{[1]}$. In processing of AMMCs, it is critical that the reinforcements disperse homogeneously into the $\mathrm{Al}$ matrix, as this plays a vital role in determining the properties ${ }^{[2]}$. Yet, the dispersion of the reinforcements is still a challenge. With the recent development of powder bed additive manufacturing (AM) techniques such as Selective Laser Melting (SLM), a homogenous dispersion of 
the reinforcements is easier to achieve ${ }^{[3-6]}$, while the density advantages of melt processing have been retained. This fabrication process also facilitates a wider choice of reinforcements and enables the microstructure to be tailored at any point in the AMMCs.

There have been several reports of using SLM to produce AMMCs. Ghosh et al. successfully fabricated Al4.5Cu3Mg/SiC AMMCs with improved hardness by direct metal laser sintering (DMLS) ${ }^{[3]}$. However, in their study, cracks were generated at the interface which were thought to form as a result of differences in thermal expansion coefficient. Ocelik et al. investigated the reaction zone at the interface between $\mathrm{Al}$ and SiC in the Al/SiC AMMCs fabricated using laser melt injection (LMI) ${ }^{[4]}$. The large amount of coherent small $\mathrm{Al}_{4} \mathrm{C}_{3}$ plates on the surface of $\mathrm{SiC}$ was thought to cause particle cracking, and act as a crack initiation site in the AMMCs. In addition, in our recent study on SLM of Al12Si/SiC ${ }^{[5]}$, a large amount of the added SiC particles were broken down when using high incident laser energies $\left(\sim 71 \mathrm{~J} / \mathrm{mm}^{3}\right)$, making the resultant microstructure and mechanical properties difficult to control. Therefore, it can be seen that the interfacial microstructure including phase formation between the $\mathrm{Al}$ matrix and the reinforcements hold the key to achieving desired properties in the AM fabricated AMMCs.

Due to the small interaction volume and short interaction time between the laser and the material, the local heating and cooling rates during SLM are very high $\left(10^{3}-10^{8}\right.$ $\mathrm{K} / \mathrm{s})^{[7]}$. This results in severe thermal and residual stresses, which arise from the steep temperature gradients, large expansions and shrinkages or non-uniform plastic deformation $^{[8]}$. It is obvious that these stresses not only complicate the physical and chemical reaction at the interface between the $\mathrm{Al}$ matrix and the reinforcements but can cause detachment of the reinforcements from the $\mathrm{Al}$ matrix due to the thermal 
expansion coefficient mismatch ${ }^{[3]}$. Residual stresses in a material can be investigated using X-ray diffraction and neutron scattering ${ }^{[9]}$. However, these studies focus on the overall distribution of residual stress and phase formation within the entire component. As a non-destructive and micro-scale analysis technique, confocal Raman microscopy has been shown to be effective in determining the local residual stress and interfacial microstructure analyses ${ }^{[10]}$. In addition, it can be very sensitive to light elements involved in covalent bonds, due to the fact that the Raman scattering efficiency depends on the polarizability of electron cloud ${ }^{[11]}$.

In this study, confocal Raman microscopy was used to investigate the interfacial microstructure and distribution of residual stresses along the interface between Al12Si and SiC within the Al12Si/SiC AMMCs fabricated by SLM. Scanning electron microscope (SEM, FEI Verios 460) with a high resolution energy dispersive X-ray spectroscopy (EDX, Oxford Instrument) was also used to investigate the interface. The relation between the residual stress and the interfacial microstructure was revealed and discussed. This work provides important information for fabrication of AMMCs with tailorable microstructure and a controllable interface.

\section{Experimental Section}

Al12Si powder (LPW Technology, UK, 20-63 $\mu \mathrm{m}, \mathrm{d}_{50} \sim 38 \mu \mathrm{m}$ ) and SiC powder (Kemet, Australia, 400 grit, diameter between 11 and $45 \mu \mathrm{m}$ ) were used in this study. SiC powder was added into the Al12Si powder to make up a volume fraction of $10 \%$ and the powder was mechanically mixed in a mixer (Turbula TF2, speed $100 \mathrm{rpm}$ ) for $30 \mathrm{~min}$ to ensure a homogeneous distribution. Then the Al12Si/SiC composite parts were produced on a ReaLizer SLM-100 machine (ReaLizer GmbH, Germany) 
which is equipped with a $1.06 \mu \mathrm{m}$ wavelength fibre laser with maximum power of $200 \mathrm{~W}$ at the part bed. The laser scan rate, hatch spacing, layer thickness and substrate temperature were $500 \mathrm{~mm} / \mathrm{s}, 0.15 \mathrm{~mm}, 50 \mu \mathrm{m}$ and $200^{\circ} \mathrm{C}$, respectively.

The Raman studies were conducted on carefully-polished samples (the influence on surface residual stresses was minimised) at room temperature with a confocal Raman backscattering technique (WITec alpha 300RA+) using a $532 \mathrm{~nm}$ excitation wavelength and a back-illuminated EMCCD (electron multiplying CCD). The laser light was coupled into the microscope using a single-mode fibre and brought on to the sample using a dichroic mirror and a $100 \times$ microscope objective (NA 0.9). The spatial resolution is about $300 \mathrm{~nm}$ with a spectral resolution of $0.02 \mathrm{~cm}^{-1}$. The integration time for collecting each spectrum was $\sim 38.78 \mathrm{~ms}$. A stress-free sample was used to calibrate the zero stress reference peak position before each measurement and the residual stress was obtained by measuring the peak shift of the fabricated samples from the stress-free sample. Due to the high-sensitive EMCCD which enables ultrafast Raman imaging, a low laser energy $(<5 \mathrm{~mW})$ was used during the entire experiment and no heating effect was seen.

\section{Results and Discussion}

An SEM image of the interface between the Al12Si matrix and the SiC in the SLM fabricated AMMCs is shown in Figure 1(a). No evidence of the prior Al12Si powder particles was observed, suggesting that the Al12Si particles were fully melted during the process. In contrast, the angular morphology of the SiC powder particles remains largely unchanged, which indicates that the laser energy was insufficient to melt the SiC particles. However, the break-down of SiC particles was also observed during 
SLM, similar to what we found in our previous study ${ }^{[5]}$. Another two distinct regions can also be seen at the interface. One region contains a dark needle-like phase while the other has lighter contrast equiaxed particles. The EDX mapping results of the area indicated by the white box in Figure 1(a) are shown in Figures 1(b)-(d). It can be seen that these two regions have different concentration of $\mathrm{Al}, \mathrm{Si}$ and $\mathrm{C}$. The needle-like phase has a high concentration of $\mathrm{C}$, while the equiaxed particles are rich in $\mathrm{Si}$. Thus, it is likely that these additional phases have formed due to the reaction between the molten Al- and SiC. That is $3 \mathrm{SiC}+4 \mathrm{Al} \rightarrow \mathrm{Al}_{4} \mathrm{C}_{3}+3 \mathrm{Si}$.

The Raman spectra of SiC particle, the Si enriched region and the $\mathrm{C}$ enriched regions are shown in Figures 2(a) to (c), respectively. The corresponding Raman intensity maps are shown as insets. From Figure 2(a), three Raman intensity peaks around 760 $\mathrm{cm}^{-1}, 791 \mathrm{~cm}^{-1}$ and $970 \mathrm{~cm}^{-1}$ can be observed, which correspond to the $\mathrm{E}_{2} \mathrm{FTO} \times(1 / 3)$, FTO $x(2 / 3)$ and FLO x(0) phonon modes of SiC respectively ${ }^{[12]}$. The Raman intensity map clearly shows the morphology of the SiC particle embedded in the Al12Si matrix. The Raman spectrum of the Si enriched region at the interface exhibits a sharp peak around $521 \mathrm{~cm}^{-1}$. This is the $\mathrm{E}_{2}$ (high) phonon mode of $\mathrm{Si}^{[13]}$. In addition, the Raman spectrum of the $C$ enriched region reveals three weak peaks around $493 \mathrm{~cm}^{-1}, 718 \mathrm{~cm}^{-}$ ${ }^{1}$ and $864 \mathrm{~cm}^{-1}$. These peaks have been attributed to be the $A_{1 g}, E_{g}$ and again $A_{1 g}$ phonon modes of aluminium carbide $\left(\mathrm{Al}_{4} \mathrm{C}_{3}\right)^{[14]}$. It is interesting to note that at each $\mathrm{Al}_{4} \mathrm{C}_{3}$, a weak peak at $521 \mathrm{~cm}^{-1}$ can be detected, which is likely to come from the neighbouring Si particles. Because the angular morphology of $\mathrm{SiC}$ is retained after SLM and there is no evidence of localised vaporisation (e.g. formation of pores around the interface), it is very unlikely that the melting or dissolution of $\mathrm{SiC}$ into the molten Al12Si matrix has occurred, which would cause the precipitation of $\mathrm{Al}_{4} \mathrm{C}_{3}$ and Si during solidification. Thus, it is reasonable to speculate that during SLM the 
Al12Si matrix reacts with the $\mathrm{SiC}$ particles to form needle-like $\mathrm{Al}_{4} \mathrm{C}_{3}$ and the equiaxed Si at the interface. This reaction is extremely slow at the low temperatures for which it is normally observed, with localised reaction products only reaching a few microns after 1 hour at $1000^{\circ} \mathrm{C}^{[15]}$. This timeframe is far beyond the interaction time ( $\leq 1 \mathrm{~ms}$ ) between the laser and the powder during SLM. However, the laser absorptivity (at a wavelength of $1.06 \mu \mathrm{m}$ ) of $\mathrm{Al} 12 \mathrm{Si}$ and $\mathrm{SiC}$ is $7 \%$ and $78 \%$ respectively ${ }^{[16]}$. Hence, significant differences in localised temperature of each phase may be occurring. The higher absorptivity of the SiC could lead to high temperature in the reinforcing particles which would facilitate reaction between $\mathrm{Al}$ and $\mathrm{SiC}$ given that the difference in specific heats of $\mathrm{SiC}\left(750 \mathrm{~J} / \mathrm{Kg} \cdot{ }^{\circ} \mathrm{C}\right)$ and $\mathrm{Al} 12 \mathrm{Si}\left(970 \mathrm{~J} / \mathrm{Kg} \cdot{ }^{\circ} \mathrm{C}\right)$ is not significant ${ }^{[17]}$. In addition, the abovementioned break-down of the SiC will provide large free surface areas which can in turn enhance this interfacial reaction. The break-down of the SiC may be facilitated by the residual stress during SLM as a result of the extremely high thermal fluctuations and thermal gradients within the AMMCs. This will be discussed in detail below. There are also two peaks located at 2910 and $2980 \mathrm{~cm}^{-1}$ while no G band and D band from carbon can be observed in Figure 2(d). This has been reported as the mode of the C-H. According to our previous study ${ }^{[18]}$, there exists a thin layer of moisture on the Al12Si powder particles, which could be ascribed for the formation of C-H.

As shown in Figure 2, both of the $\mathrm{E}_{2} \mathrm{FTO} \times(2 / 3)$ phonon mode for $\mathrm{SiC}$ and $\mathrm{E}_{2}$ (high) phonon mode for $\mathrm{Si}$ in the interface region shift to a lower wavelength number compared to the stress-free $\mathrm{SiC}$ and $\mathrm{Si}$, respectively. This suggests that both $\mathrm{SiC}$ and Si are in tensile stress state, probably a result of the formation of residual stresses due to the thermal fluctuations and thermal gradients during SLM. In order to investigate the distribution of the stress in the interface region between SiC and Al12Si matrix, 
Raman scattering was conducted along two different directions (lines) along the interface and the results are shown in Figure 3. One direction was along the build direction (Z) and the other was in X-Z direction, perpendicular to the build direction. To obtain accurate Raman frequency peaks, all the Raman spectra were fitted with Lorentz curves. It is known that Al12Si has a higher coefficient of thermal expansion (CTE) $\sim 22.3 \times 10^{-6} /{ }^{\circ} \mathrm{C}^{[19]}$ than $\mathrm{SiC} \sim 4.0 \times 10^{-6} /{ }^{\circ} \mathrm{C}^{[20]}$ which means that compressive stresses would be expected in SiC particles. However, it can be seen that along both directions (lines) the $\mathrm{SiC}$ and $\mathrm{Si}$ are in tensile stress state (Figure 3). As mentioned above, the SiC absorbs more laser energy and was likely to be heated to a higher temperature than the Al12Si matrix. Thus the SiC particles would have acted as a heat source to locally increase the temperature of the neighbouring Al12Si matrix. As such, the $\mathrm{SiC}$ particle and the surrounding matrix may have reached a higher temperature during SLM than other parts of the AMMC. Hence, the SiC and its neighbouring Al12Si matrix will have expanded more during laser heating while the surrounding unmelted Al12Si region acts as a constraint. This results in the formation of compressive stresses within the $\mathrm{SiC}$ and the neighbouring Al12Si during laser heating. During cooling, this region will shrink due to thermal contraction, which induces a tensile stress in this region. This is likely the cause of the observed tensile stress in SiC and its neighbouring Al12Si matrix. However, future studies from a quantitative aspect would help provide a deeper understanding of the underlying mechanism for the formation of this tensile stress.

The tensile stress in $\mathrm{SiC}$ along the $\mathrm{Z}$ direction is also higher than the tensile stress in $\mathrm{SiC}$ along the $\mathrm{X}-\mathrm{Z}$ direction. It is known that the laser energy density in SLM has a Gaussian distribution and the convection in the melt pool during SLM tends to dominate at a high laser power ${ }^{[21]}$. Both these factors will enhance the heat flow in the 
$\mathrm{X}-\mathrm{Z}$ direction more than that along the $\mathrm{Z}$ direction, resulting in the melt pool having a Gaussian distribution like morphology. This results in a steeper thermal gradient and thus a lower temperature in the $\mathrm{X}-\mathrm{Z}$ direction than along the $\mathrm{Z}$ direction. The higher temperature along the $\mathrm{Z}$ direction will make the expansion of the $\mathrm{SiC}$ and its neighbouring Al12Si matrix much stronger in this direction while the constraint from other parts of the AMMC also becomes more pronounced. Therefore in the $\mathrm{Z}$ direction, the tensile stress in $\mathrm{SiC}$ is higher than that along the $\mathrm{X}-\mathrm{Z}$ direction. However, the tensile stress in Si along both directions seems to be essentially identical. This is probably caused by the phase transformation in the interface region between SiC and Al12Si mentioned above, which could help relieve the residual stresses. The relation between the TO peak shift $\Delta \omega=\omega-\omega_{0}$ and the stress $\sigma$ in SiC can be estimated using the equation $\Delta \omega=\omega-\omega_{0}=\mathrm{K} \sigma^{[22]}$, where $\omega$ and $\omega_{0}$ are the TO phonon frequencies of measured $\mathrm{SiC}$ and a stress-free $\mathrm{SiC}$, respectively and $\mathrm{K}\left(\mathrm{cm}^{-1} / \mathrm{GPa}\right)$ is a constant and equals to $3.11 \mathrm{~cm}^{-1} / \mathrm{GPa}$. The relation between the peak shift and the stress in Si can also be estimated based on the above equation where K equals to 1.93 $\mathrm{cm}^{-1} / \mathrm{GPa}^{[23]}$. According to this, the tensile stress in the SiC along the $\mathrm{X}-\mathrm{Z}$ and $\mathrm{Z}$ directions has been estimated, which has an average value around 240 and $570 \mathrm{MPa}$, respectively. This tensile stress in $\mathrm{SiC}$ can facilitate the break-down of the intrinsically brittle SiC. Similarly, the tensile stress along both directions in Si is calculated to be around $75 \mathrm{MPa}$.

\section{Conclusion}

In summary, the interfacial reaction products and stress distribution in Selective Laser Melted Al12Si/SiC have been studied using confocal Raman microscopy. Two 
distinct regions with different $\mathrm{Al}, \mathrm{C}$ and $\mathrm{Si}$ concentrations were observed by EDX. The $\mathrm{C}$ enriched region and the $\mathrm{Si}$ enriched region are confirmed by Raman spectroscopy to be $\mathrm{Al}_{4} \mathrm{C}_{3}$ and $\mathrm{Si}$, respectively. This interface reaction is thought to be caused by the elevated temperature in the SiC, which in turn is a consequence of its high laser absorptivity. The Raman frequency of both the SiC and Si shifts to lower wavenumber, indicating the presence of tensile stresses at the interface. The tensile stress in the SiC was measured to be higher in the build direction (Z) compared to that in the direction (X-Z) perpendicular to the build direction, while no such difference being observed in $\mathrm{Si}$. The underlying reason was ascribed to the Gaussian distribution of the laser energy density and stress relief through the interfacial reaction.

\section{References}

[1] B. V. Ramnath, C. Elanchezhian, R. Annamalai, S. Aravind, T. S. A. Atreya, V. Vignesh, C. Subramanian, Rev. Adv. Mater. Sci 2014, 38, 55.

[2] M. Surappa, Sadhana 2003, 28, 319.

[3] S. K. Ghosh, P. Saha, Mater. Des. 2011, 32, 139.

[4] V. Ocelík, J. A. Vreeling, J. T. M. De Hosson, J. Mater. Sci. 2001, 36, 4845.

[5] T. B. Sercombe, X. Li, Mater. Technol. 2016, 31, 77.

[6] B. Song, S. Dong, C. Coddet, Scripta Mater. 2014, 75, 90; B. Song, S. Dong, P. Coddet, G. Zhou, S. Ouyang, H. Liao, C. Coddet, J. Alloys Compd. 2013, 579, 415.

[7] X. P. Li, M. Roberts, Y. J. Liu, C. W. Kang, H. Huang, T. B. Sercombe, Mater. Des. 2015, 65, 1; T. Vilaro, V. Kottman-Rexerodt, M. Thomas, C. Colin, P. Bertrand, L. Thivillon, S. Abed, V. Ji, P. Aubry, P. Peyre, T. Malot, Adv. Mater. Res. 2010, 586. 
[8] D. Gu, W. Meiners, K. Wissenbach, R. Poprawe, Int. Mater. Rev. 2012, 57, 133; B. Song, S. Dong, Q. Liu, H. Liao, C. Coddet, Mater. Des. 2014, 54, 727; B. Song, X. Zhao, S. Li, C. Han, Q. Wei, S. Wen, J. Liu, Y. Shi, Front Mech. Eng. 2015, 10, 111.

[9] M. Agamalian, E. Iolin, H. Kaiser, C. Rehm, S. A. Werner, Phys. Rev. B 2001, 64;

G. Chen, C. Wan, Appl. Phys. Lett. 2010, 96.

[10] S. Nagarajan, O. Svensk, L. Lehtola, H. Lipsanen, M. Sopanen, Appl. Phys. Lett. 2014, 104, 151906; Z. Xiao, Y. Yang, X. Luo, B. Huang, Appl. Phys. Lett. 2014, 104, 081611; X. Li, X. Wang, M. Saunders, A. Suvorova, L. Zhang, Y. Liu, M. Fang, Z. Huang, T. Sercombe, Acta Mater. 2015, 95, 74.

[11] E. Smith, G. Dent, Modern Raman spectroscopy: a practical approach, John Wiley \& Sons, 2013.

[12] S. Lin, Z. Chen, L. Li, C. Yang, Mater. Res. 2012, 15, 833.

[13] G. Yue, J. D. Lorentzen, J. Lin, D. Han, Q. Wang, Appl. Phys. Lett. 1999, 75, 492.

[14] J. L. Kennedy, T. D. Drysdale, D. H. Gregory, Green Chem. 2015, 17, 285; Y. Sun, H. Cui, L. Gong, J. Chen, J. She, Y. Ma, P. Shen, C. Wang, ACS Nano 2011, 5, 932.

[15] J. C. Viala, P. Fortier, J. Bouix, J. Mater. Sci. 1990, 25, 1842.

[16] N. K. Tolochko, Y. V. Khlopkov, S. E. Mozzharov, M. B. Ignatiev, T. Laoui, V. I. Titov, Rapid prototyp. J. 2000, 6, 155; E. M. R. Silva, W. A. Monteiro, W. Rossi, M. S. F. Lima, J. Mater. Sci. Lett. 2000, 19, 2095.

[17] J. G. Kaufman, E. L. Rooy, Aluminum alloy castings: properties, processes, and applications, Asm International, 2004; R. G. Munro, J. Phys. Chem. Ref. Data 1997, 26, 1195. 
[18] X. P. Li, K. M. O’Donnell, T. B. Sercombe, Additive Manufacturing 2016, 10, 10.

[19] S. Q. Wu, Z. S. Wei, S. C. Tjong, Compos. Sci. Technol. 2000, 60, 2873.

[20] D. N. Talwar, J. C. Sherbondy, Appl. Phys. Lett. 1995, 67, 3301.

[21] X. P. Li, C. W. Kang, H. Huang, L. C. Zhang, T. B. Sercombe, Mater. Sci. Eng., A 2014, 606, 370.

[22] J. Liu, Y. K. Vohra, Phys. Rev. Lett. 1994, 72, 4105.

[23] I. De Wolf, H. E. Maes, S. K. Jones, J. Appl. Phys. 1996, 79, 7148.

\section{Figure Captions}

Fig.1 (a) SEM image of the interface between the Al12Si matrix and the SiC in the SLM fabricated AMMCs; (b) to (d) EDS mapping of Al, Si and C (rectangular area in (a)). Arrows in red and yellow point to the $\mathrm{C}$ enriched and $\mathrm{Si}$ enriched regions, respectively.

Fig.2 Raman spectra (in black) and phonon peak position fitted with Lorentzian line (in red) of the $\mathrm{SiC}$ particle, the Si enriched region and the $\mathrm{C}$ enriched region. The inset shows the corresponding Raman intensity map. Black dotted lines show the peak positions of the $\mathrm{E}_{2} \mathrm{FTO} \times(2 / 3)$ phonon mode for $\mathrm{SiC}$ and $\mathrm{E}_{2}$ (high) phonon mode for $\mathrm{Si}$ in standard stress-free $\mathrm{SiC}$ and $\mathrm{Si}$, respectively.

Fig.3 Raman frequencies of the FTO phonon mode of $\mathrm{SiC}$ and $\mathrm{E}_{2}$ phonon mode of $\mathrm{Si}$ along two different directions: $\mathrm{Z}$ and $\mathrm{X}-\mathrm{Z}$. Frequencies are measured exactly along the white arrows at the interface in the inset image. Black dotted lines show the peak 
positions of the $\mathrm{E}_{2} \mathrm{FTO} \times(2 / 3)$ phonon mode for $\mathrm{SiC}$ and $\mathrm{E}_{2}$ (high) phonon mode for $\mathrm{Si}$ in standard stress-free $\mathrm{SiC}$ and $\mathrm{Si}$, respectively. 


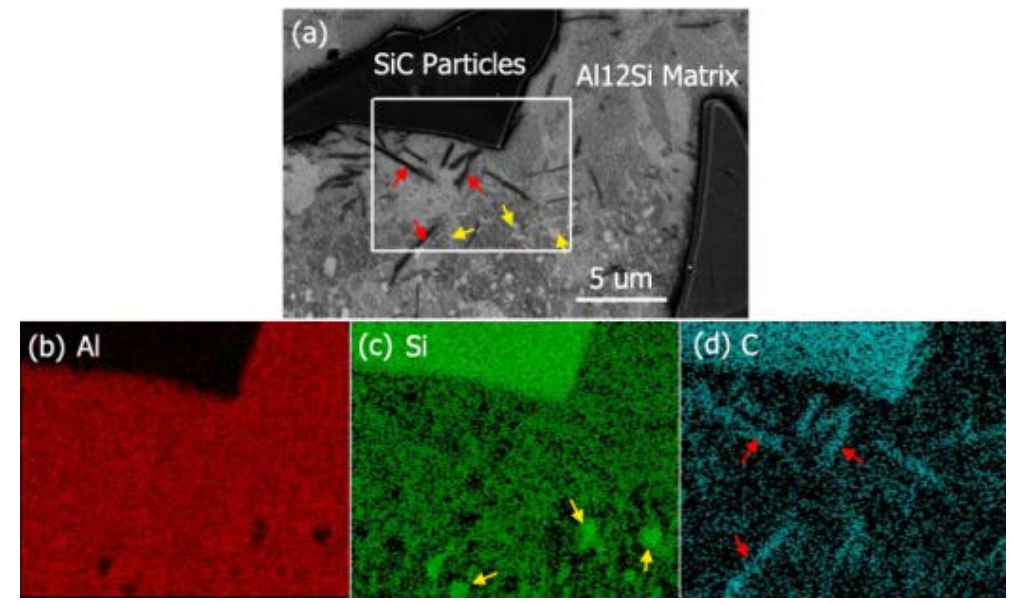

FIG.1 (a) SEM image of the interface between the Al12Si matrix and the SiC in the SLM fabricated AMMCs; (b) to (d) EDS mapping of Al, Si and C (rectangular area in (a)). Arrows in red and yellow point to the $\mathrm{C}$ enriched and Si enriched regions, respectively. 


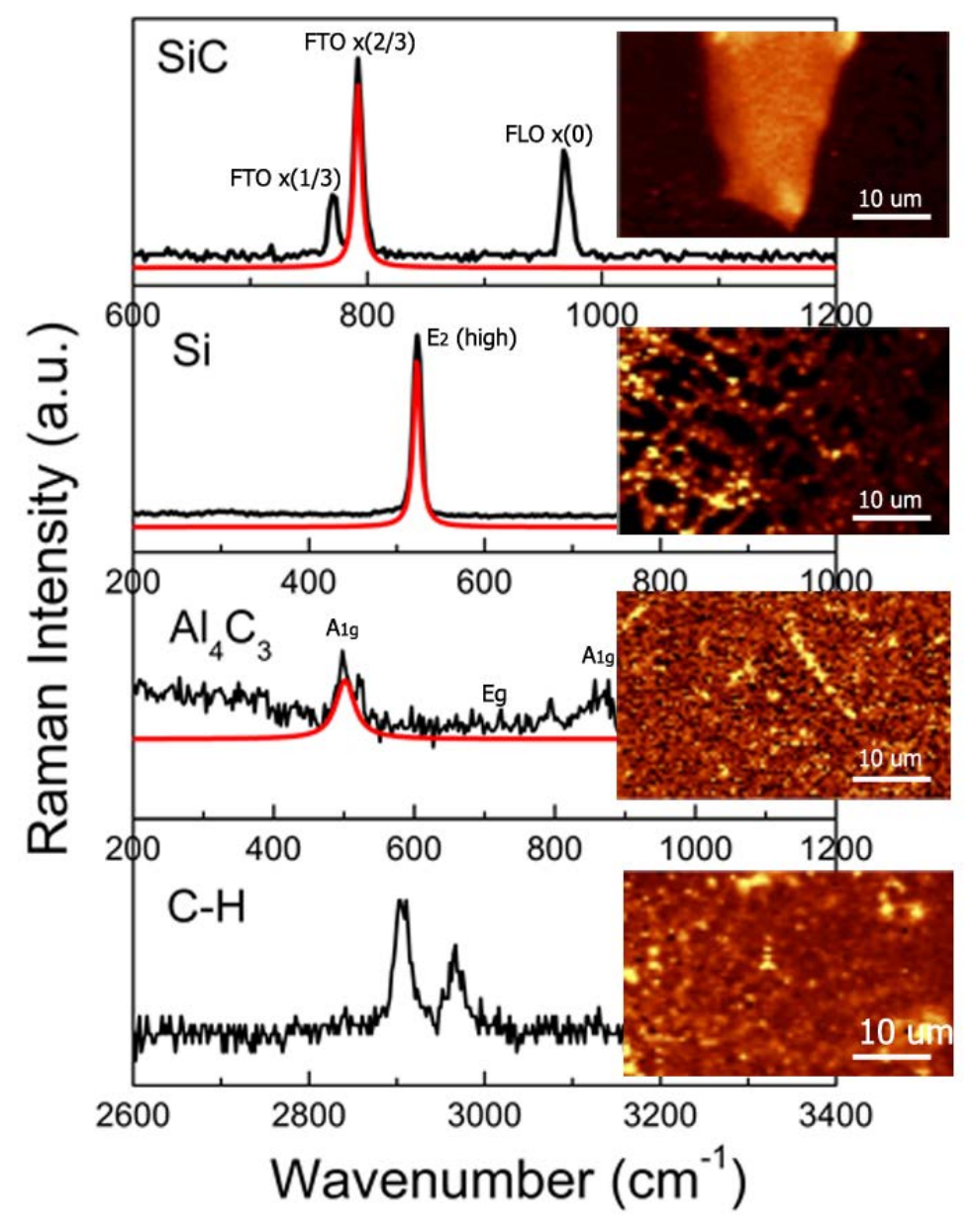

FIG.2 Raman spectra (in black) and phonon peak position fitted with Lorentzian line (in red) of the $\mathrm{SiC}$ particle, the Si enriched region and the $\mathrm{C}$ enriched region. The inset shows the corresponding Raman intensity mapping. 


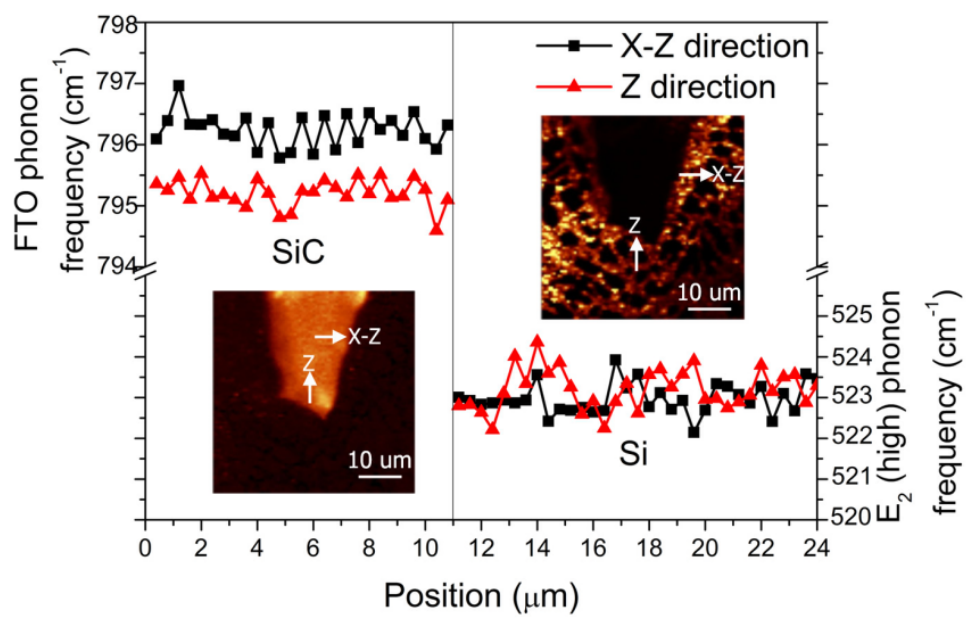

FIG.3 Raman frequencies of the FTO phonon mode of SiC and $\mathrm{E}_{2}$ phonon mode of Si along two different directions: $\mathrm{Z}$ and $\mathrm{X}-\mathrm{Z}$. Frequencies are measured along the white arrows in the inset image. 